Article

\title{
Evaluation of Spatiotemporal Variations of Global Fractional Vegetation Cover Based on GIMMS NDVI Data from 1982 to 2011
}

\author{
Donghai Wu ${ }^{1}$, Hao $\mathrm{Wu}^{2}$, Xiang Zhao ${ }^{1{ }^{*},}$, Tao Zhou ${ }^{2}$, Bijian Tang ${ }^{1}$, Wenqian Zhao ${ }^{1}$ \\ and Kun Jia ${ }^{1}$
}

1 College of Global Change and Earth System Science, Beijing Normal University, Beijing 100875, China; E-Mails: donghai@mail.bnu.edu.cn (D.W.); tangbj@mail.bnu.edu.cn (B.T.); wenqianzhao@mail.bnu.edu.cn (W.Z.); jiakun@bnu.edu.cn (K.J.)

2 State Key Laboratory of Earth Surface Processes and Resource Ecology, Beijing Normal University, Beijing 100875, China; E-Mails: wuhaogis@163.com (H.W.); tzhou@bnu.edu.cn (T.Z.)

* Author to whom correspondence should be addressed; E-Mail: zhaoxiang@bnu.edu.cn; Tel.: +86-10-5880-4539; Fax: +86-10-5880-4539.

Received: 19 December 2013; in revised form: 27 March 2014 / Accepted: 16 April 2014 / Published: 5 May 2014

\begin{abstract}
Fractional vegetation cover (FVC) is an important biophysical parameter of terrestrial ecosystems. Variation of FVC is a major problem in research fields related to remote sensing applications. In this study, the global FVC from 1982 to 2011 was estimated by GIMMS NDVI data, USGS global land cover characteristics data and HWSD soil type data with a modified dimidiate pixel model, which considered vegetation and soil types and mixed pixels decomposition. The evaluation of the robustness and accuracy of the GIMMS FVC with MODIS FVC and Validation of Land European Remote sensing Instruments (VALERI) FVC show high reliability. Trends of the annual $\mathrm{FVC}_{\max }$ and $\mathrm{FVC}_{\text {mean }}$ datasets in the last 30 years were reported by the Mann-Kendall method and Sen's slope estimator. The results indicated that global FVC change was 0.20 and 0.60 in a year with obvious seasonal variability. All of the continents in the world experience a change in the annual $\mathrm{FVC}_{\max }$ and $\mathrm{FVC}_{\text {mean }}$, which represents biomass production, except for Oceania, which exhibited a significant increase based on a significance level of $p=0.001$ with the Student's t-test. Global annual maximum and mean FVC growth rates are $0.14 \% / y$ and $0.12 \% / y$, respectively. The trends of the annual $\mathrm{FVC}_{\max }$ and $\mathrm{FVC}_{\text {mean }}$ based on pixels also illustrated that the global vegetation had turned green in the last 30 years. A significant trend on the $p=0.05$ level was found for $15.36 \%$ of the GIMMS $\mathrm{FVC}_{\max }$ pixels on a global scale (excluding permanent
\end{abstract}


snow and ice), in which $1.8 \%$ exhibited negative trends and $13.56 \%$ exhibited positive trends. The GIMMS $\mathrm{FVC}_{\text {mean }}$ similarly produced a total of $16.64 \%$ significant pixels with $2.28 \%$ with a negative trend and $14.36 \%$ with a positive trend. The North Frigid Zone represented the highest annual $\mathrm{FVC}_{\max }$ significant increase $(p=0.05)$ of $25.17 \%$, which may be caused mainly by global warming, Arctic sea-ice loss and an advance in growing seasons. Better FVC predictions at large regional scales, with high temporal resolution (month) and long time series, would advance our ability to understand the characteristics of the global FVC changes in the last 30 years and predict the response of vegetation to global climate change.

Keywords: GIMMS; FVC; trend; dimidiate pixel model; Mann-Kendall; Sen's slope estimator

\section{Introduction}

Vegetation is the natural link connecting soil, atmosphere and water, and it plays important roles in maintaining the global ecological balance [1]. Fractional vegetation cover (FVC) can respond to the surface vegetation status directly and is an important quantitative index of vegetation and ecosystem changes [2-4]. The FVC commonly represents a Normalized Difference Vegetation Index (NDVI) derived vegetation parameter that is defined as the ratio of the vertical projection area, which includes plants' branches, stalks and leaves, to the total vegetation area [5]. As a quantitative parameter, the FVC is an important indicator for studying the aerosphere, pedosphere, hydrosphere and biosphere, as well as their interactions. FVC is also a crucial biophysical parameter to reveal the land surface coverage status of the planet, as well as measurable global change [6-8]. Accurate estimation of the FVC is required for research on land-surface processes, climate change and numerical weather predictions [9]. The dimidiate pixel method [2], the most widely used regression model to study the FVC, is used for this study.

Normally, the dimidiate pixel model uses MODIS or AVHRR NDVI data to invert FVC, and the accuracy of the inverted FVC data is based on two statistical parameters, $\mathrm{NDVI}_{\text {soil }}$ and $\mathrm{NDVI}_{\mathrm{veg}}$, in Equation (1) [7,10]. Previous studies have performed a lot of work related to the determination of $\mathrm{NDVI}_{\text {soil }}$ and $\mathrm{NDVI}_{\mathrm{veg}}[2,7,11]$. Gutman and Ignatov used a universal value of 0.52 for $\mathrm{NDVI}_{\mathrm{veg}}$ and 0.04 for $\mathrm{NDVI}_{\text {soil }}$ to derivate global FVC with the NOAA/AVHRR NDVI dataset [2]. These two parameters are popular, because of their ease of implementation. However, considering the differences between vegetation types, Zeng et al. optimized the model for different vegetation types that have different $\mathrm{NDVI}_{\mathrm{veg}}$ values $[9,11]$. In addition, different soil types have different NDVI values, and Montandon and Small took the impact of soil reflectance on the quantification of the green vegetation fraction into account to invert FVC. They compiled 2906 reflectance spectra of soils collected worldwide to calculate the NDVI values of these soils and used this soil composite dataset to calculate the statistically most likely FVC estimate that, unlike current methods, does not use a single soil NDVI value, but takes into account the observed soil NDVI variability to produce an adjusted FVC [7]. Montandon and Small's study indicates that the average NDVI of the 2906 soil samples calculated using AVHRR spectral response functions is 0.20 with a standard deviation of 0.09 . The histograms of soil NDVI values follow normal distributions, so the range of soil NDVI is $0.02-0.38$ at the $p=0.05$ level. Therefore, it is 
inadequate to use an invariant value of 0.05 or 0.04 , as in Zeng and Gutman's studies. It is better to collect soil spectra from as many soil types as possible; however, it is extremely difficult, and there is no specification to collect different types of soil spectra.

In this study, both the vegetation and soil types were considered to retrieve FVC. Global land cover data and global soil data were used to establish a set of unified threshold standards with the NDVI dataset. To evaluate global spatiotemporal FVC variations, GIMMS NDVI data, which is one of the longest time series NDVI datasets, lasting 30 years, was chosen. Because most GIMMS NDVI pixels include more than one vegetation or soil type, mixed pixel decomposition is also considered in this study.

Research on the long time series GIMMS NDVI datasets showed that the linear time trends in Eurasia (North America) increased by $12.41 \%$ (8.44\%) during the growing season from April to October in 1981 to 1999 , which are statistically significant at the 5\% level [12]. In addition, a significant trend in GIMMS NDVI $(p=0.05)$ was found for $10.05 \%$ pixels on a global scale $(4.9 \%$ characterized by positive trends and $5.6 \%$ with negative trends) in last 10 years [13]. Nevertheless, what are the characteristics of the global FVC status and trends in last 30 years from 1982 to 2011? In this study, we used the GIMMS NDVI dataset to retrieve global FVC from the past 30 years with the modified dimidiate pixel method. We used non-parametric tests for the trend analysis of time series data, called the Mann-Kendall method, and Sen's slope estimator. The method was applied to determine the vegetation coverage variation trends for all of the continents.

\section{Data}

\subsection{GIMMS and MODIS NDVI Data}

The NDVI dataset used in this study was from the Global Inventory Monitoring and Modeling Systems (GIMMS) group at the Laboratory for Terrestrial Physics from July 1981 to December 2011 [14]. The GIMMS NDVI dataset was derived at a spatial resolution of $1 / 12^{\circ}(10 \mathrm{~km})$ and a 15 -day interval. A post-processing satellite drift correction was applied to the dataset to remove artifacts due to the orbital drift and changes in the sun-target-sensor geometry [15]. This dataset is more sensitive to water vapor in the atmosphere as a result of the AVHRR's wide spectral bands [16]. An increase in water vapor results in a lower NDVI signal, which can be interpreted as an actual change if no correction is applied [17]. The maximum value composite (MVC) method [18] should lessen these artifacts. The MVC approach was applied to the original GIMMS 15-day NDVI composite data, which spanned 30 years from January 1982 to December 2011, to aggregate monthly data to reduce the influence from clouds in the later data analysis [18].

Because of the low spatial resolution of GIMMS NDVI data, we also tested the robustness and accuracy of the results with the MOD13A3 monthly vegetation indices dataset, which was derived at a spatial resolution of $1 \mathrm{~km}$ from 2000 to 2012. In generating this monthly product, the algorithm ingests all of the 16-day 1-km products that overlap the month and employs a weighted temporal average if data is cloud free or a maximum value in the case of clouds [19,20]. MODIS vegetation indices are widely used for global monitoring of vegetation conditions and are used in products displaying land cover and land cover changes [13]. 


\subsection{Global Land Cover Data}

The USGS global land cover characteristics database, version 2.0, was used in this study [21,22]. The dataset is derived from 1-km Advanced Very High Resolution Radiometer (AVHRR) data spanning a 12-month period (April 1992 to March 1993) and is based on a flexible database structure and seasonal land cover region concepts. The IGBP global vegetation classification scheme $[23,24]$ is used, which includes 11 natural vegetation classes, 3 developed and mosaicked land classes and three non-vegetated land classes. The Collection 5.1 MODIS land cover product (MCD12Q1), which includes adjustments for significant errors that were detected in Collection 5 [24,25], was also used in this study to evaluate the robustness of the modified model. It is an annual product from 2001 to 2011 with a spatial resolution of $500 \mathrm{~m}$, and the IGBP classification scheme is used in the study.

\subsection{Global Soil Data}

The Harmonized World Soil Database (HWSD) Version 1.21 was produced by the International Institute for Applied Systems Analysis (IIASA) and the Food and Agriculture Organization of the United Nations (FAO) in 2012. The HWSD is composed of a GIS raster image file linked to an attribute database in Microsoft Access format, which can be linked through a commercial GIS system. The global soil dataset contains 28 major soil groups with a spatial resolution of $1 \mathrm{~km}$ [26]. We extracted 1-km global raster image of the soil types with ArcGIS to apply the modified FVC model.

\subsection{Field Validation Data}

To testify to the precision of the produced global FVC and the reliability of the modified model, validation data was used from the Validation of Land European Remote sensing Instruments (VALERI) project, which provided high spatial resolution maps of FVC estimated from ground measurements to validate products derived from satellite observations. There were 18 sites chosen according to uniform land cover pixels to evaluate our results.

\section{Methods}

\subsection{Vegetation Coverage Estimation}

As the best indication of FVC and the vegetation growth state, the NDVI's value is in $(-1,1)$. According to the dimidiate pixel model $[2,9,27]$, each pixel is composed of only two components: vegetation and non-vegetation. The spectral information results from linear mixing of the two components. The proportional area of each component in the pixel is the weight of each component. The proportional area of vegetation is the FVC of the pixel, as mathematically expressed using the formula below:

$$
f_{c}=\frac{N D V I-N D V I_{\text {soil }}}{N D V I_{\text {veg }}-N D V I_{\text {soil }}}
$$

where $f_{c}$ is the fractional vegetation cover (FVC) in the mixed pixel, NDVI is the NDVI of the mixed pixel, $\mathrm{NDVI}_{\text {soil }}$ is the NDVI of bare soil and $\mathrm{NDVI}_{\mathrm{veg}}$ is the NDVI of the vegetation. It is clear that this dimidiate pixel model is a linear regression model for VI, and the accuracy of the results of the dimidiate pixel model depend on the value of $\mathrm{NDVI}_{\text {soil }}$ and $\mathrm{NDVI}_{\mathrm{veg}}$. 
Table 1. Values of GIMMS NDVI ${ }_{\text {vegi }}$ and NDVI $_{\text {soilj }}$ used in this study.

\begin{tabular}{lcccccccc}
\hline No. & IGBP Land Cover Type & NDVI $_{\text {veg }}$ & No. & $\begin{array}{c}\text { HWSD Soil }^{\text {Group }} \\
\text { NDVI }_{\text {soil }}\end{array}$ & No. & $\begin{array}{c}\text { HWSD Soil }_{\text {Group }} \\
\text { NDVI }\end{array}$ soil \\
\hline 01 & Evergreen needleleaf forest & 0.92 & 01 & Acrisols & 0.33 & 16 & Leptosols & 0.16 \\
02 & Evergreen broadleaf forest & 0.92 & 02 & Alisols & 0.34 & 17 & Luvisols & 0.24 \\
03 & Deciduous needleleaf forest & 0.90 & 03 & Andosols & 0.25 & 18 & Lixisols & 0.29 \\
04 & Deciduous broadleaf forest & 0.95 & 04 & Arenosols & 0.18 & 19 & Nitisols & 0.32 \\
05 & Mixed forest & 0.93 & 05 & Anthrosols & 0.14 & 20 & Podzoluvisols & 0.21 \\
06 & Closed shrublands & 0.94 & 06 & Chernozems & 0.14 & 21 & Phaeozems & 0.20 \\
07 & Open shrublands & 0.94 & 07 & Calcisols & 0.12 & 22 & Planosols & 0.27 \\
08 & Woody savannas & 0.86 & 08 & Cambisols & 0.22 & 23 & Plinthosols & 0.30 \\
09 & Savannas & 0.70 & 09 & Fluvisols & 0.22 & 24 & Podzols & 0.23 \\
10 & Grasslands & 0.62 & 10 & Ferralsols & 0.34 & 25 & Regosols & 0.21 \\
11 & Permanent wetlands & 0.91 & 11 & Gleysols & 0.22 & 26 & Solonchaks & 0.09 \\
12 & Croplands & 0.85 & 12 & Greyzems & 0.14 & 27 & Solonetz & 0.15 \\
13 & Urban and built-up & 0.83 & 13 & Gypsisols & 0.08 & 28 & Vertisols & 0.25 \\
14 & Cropland/natural vegetation mosaic & 0.89 & 14 & Histosols & 0.21 & & & \\
16 & Barren or sparsely vegetated & 0.94 & 15 & Kastanozems & 0.12 & & & \\
\hline
\end{tabular}

Because the area of GIMMS NDVI pixels is one hundred times larger than the area of land cover and soil pixels, it is necessary to consider mixed pixels, which contain more than one vegetation type or soil group. If there are $m$ types of vegetation and $n$ groups of soil in a pixel, the $\mathrm{NDVI}_{\mathrm{veg}}$ and $\mathrm{NDVI}_{\text {soil }}$ of the pixel are defined as follows:

$$
\begin{aligned}
& N D V I_{\text {veg }}=\sum_{i=1}^{i=m}\left(p_{i} * N D V I_{\text {veg } i}\right) ; \sum_{i=1}^{i=m}\left(p_{i}\right)=1 ; m \geq 1 \\
& N D V I_{\text {soil }}=\sum_{j=1}^{j=n}\left(q_{j} * N D V I_{\text {soilj }}\right) ; \sum_{j=1}^{j=m}\left(q_{j}\right)=1 ; n \geq 1
\end{aligned}
$$

where $p_{i}\left(q_{i}\right)$ represents the percentage of $\mathrm{NDVI}_{\text {vegi }}\left(\mathrm{NDVI}_{\text {soilj }}\right)$ in one pixel, $\mathrm{NDVI}_{\text {vegi }}\left(\mathrm{NDVI}_{\text {soilj }}\right)$ represents the value of the vegetation (soil) type in a pure pixel. Therefore, Equation (1) can be written as follows:

$$
f_{c}=\frac{N D V I-\sum_{j=1}^{j=n}\left(q_{j} * N D V I_{\text {soilj }}\right)}{\sum_{i=1}^{i=m}\left(p_{i} * N D V I_{\text {vegi }}\right)-\sum_{j=1}^{j=n}\left(q_{j} * N D V I_{\text {soilj }}\right)}
$$

In this study, statistics data were based on the pure pixels, which contain only one type of vegetation

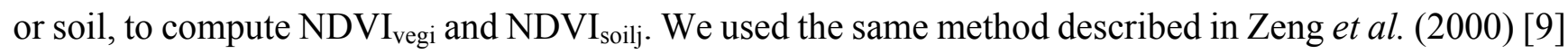
to calculate the $\mathrm{NDVI}_{\mathrm{vegi}}$ for each IGBP land cover type. First, we calculated the annual maximum NDVI image from 1992 to 1993 pixel by pixel. Second, histograms of the annual maximum images from 1992-1993 were calculated for each IGBP category of the corresponding years. Third, NDVI vegi was taken as the 75th percentile for the IGBP Categories 1-5, 8-12 and 14 and the 90th percentile for

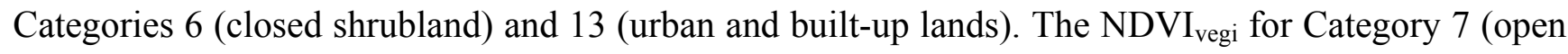
shrubland) or 16 (barren or sparsely vegetated) was taken to be the same as that for Category 6. Finally, the averaged previous statistical values from 1992 to 1993 for each IGBP category were defined as the $\mathrm{NDVI}_{\text {vegi. }}$ The $\mathrm{NDVI}_{\text {vegi }}$ values so determined are given in Table 1. We generated statistics from the annual minimum 1992-1993 images with the HWSD dataset to calculate the $\mathrm{NDVI}_{\text {soilj }}$ for each soil 
group. The prior hypothesis was that the NDVI value in the annual minimum image, which ranges between 0.02 and 0.38 , is considered as the soil area. First, the annual minimum NDVI images for 1992-1993 were calculated. Second, the $\mathrm{NDVI}_{\text {soilj }}$ for each group was defined as the average of annual minimum NDVI value during 0.02 and 0.38 in each soil group area. At the end, the averaged previous statistical values from 1992 to 1993 for each soil category were defined as the $\mathrm{NDVI}_{\text {soilj. The }} \mathrm{NDVI}_{\text {soilj }}$ values so determined are given in Table 1. Finally, the $\mathrm{NDVI}_{\text {vegi }}$ and $\mathrm{NDVI}_{\text {soilj }}$ were put into Equation (4), and the monthly FVC from 1982-2011 was calculated. We did not consider the changes of global land cover and soil, because there were no real-time datasets. The pixels with negative value were set to 0 , and the pixels with values larger than 1 were set to 1 . Permanent snow, water and unclassified pixels were masked.

\subsection{Trend Analysis Method}

\subsubsection{Mann-Kendall Methods}

The significance of the time series trends was calculated by the non-parametric Mann-Kendall (MK) significance test $[28,29]$. The MK is a rank-based procedure that compares the relative magnitudes of sample data rather than the data themselves [30]. The advantage of this method is that the data does not conform to any particular distribution, and it has a low sensitivity to abrupt breaks, due to the inhomogeneous time series [31]. It is often used for trend detection in a long time series of meteorological and hydrological records [32-35]. For a time series $X=\left\{x_{1}, x_{2}, \ldots x_{n}\right\}$, the Mann-Kendall test statistic is calculated as

$$
S=\sum_{i=1}^{n-1} \sum_{j=i+1}^{n} \operatorname{sgn}\left(x_{j}-x_{i}\right)
$$

where $n$ is the number of data points, $x_{i}$ and $x_{j}$ are the data values in time series $i$ and $j(j>i)$, respectively, and $\operatorname{sgn}\left(x_{j}-x_{i}\right)$ is the sig function as follows:

$$
\operatorname{sgn}\left(x_{j}-x_{i}\right)=\left\{\begin{array}{c}
+1, \text { if } x_{j}-x_{i}>0 \\
0, \text { if } x_{j}-x_{i}=0 \\
-1, \text { if } x_{j}-x_{i}<0
\end{array}\right.
$$

The variance is computed by:

$$
\operatorname{Var}(S)=\frac{n(n-1)(2 n+5)-\sum_{i=1}^{m} t_{i}\left(t_{i}-1\right)\left(2 t_{i}+5\right)}{18}
$$

where $n$ is the number of data points, $m$ is the number of tied groups and $t_{i}$ denotes the number of ties of extent $i$. A tied group is a set of sample data with the same value. In cases where the sample size is more than 10 , the standard normal test statistic, $Z s$, is computed by:

$$
Z_{S}=\left\{\begin{array}{c}
S-1 / \sqrt{\operatorname{Var}(S)}, \text { if } S>0 \\
0, \text { if } S=0 \\
S+1 / \sqrt{\operatorname{Var}(S)}, \text { if } S<0
\end{array}\right.
$$

Positive values of $Z s$ indicate increasing trends, while negative $Z s$ values show decreasing trends [36]. The trend's significance is assessed by comparing the $Z$ value with the standard normal variance at the pre-specified level of statistical significance [37]. The null hypothesis is rejected, and a 
significant time series trend exists when $\left|Z_{S}\right|>\mathrm{Z}_{1-\alpha / 2} \cdot \mathrm{Z}_{1-\alpha / 2}$ is obtained from the standard normal distribution table. In this study, significance levels $\alpha=0.05, \alpha=0.01$ and $\alpha=0.001$ were used, which correspond to $\mathrm{Z}_{1-\alpha / 2}$ values of $1.960,2.576$ and 3.295, respectively.

\subsubsection{Sen's Slope Estimator}

The true slope can be estimated by using a non-parametric method developed by Sen [38], if a linear trend is present by the Mann-Kendall method. The slope estimator of $\mathrm{N}$ pairs of data are first computed by:

$$
Q_{i}=\frac{x_{j}-x_{k}}{j-k}, \text { for } i=1, \ldots, N
$$

where $\mathrm{N}=\mathrm{n} \times(\mathrm{n}-1) / 2$ when there is only one datum in each time period, while $\mathrm{N}<\mathrm{n} \times(\mathrm{n}-1) / 2$ when there are multiple observations in one or more time periods, where $n$ is the total number of observations [39].

The median of these N values of Qi is the slope of Sen's estimator. If N is odd, then Sen's estimator is computed by:

$$
Q_{m e d}=Q_{[(N+1) / 2]}
$$

If $\mathrm{N}$ is even, then Sen's estimator is computed by:

$$
Q_{\text {med }}=0.5\left(Q_{[n / 2]}+Q_{[(N+2) / 2]}\right)
$$

\subsubsection{Serial Correlation Effect}

To remove serial correlation from the series and to pre-whiten the series before applying the Mann-Kendall and Sen's slope estimator, a method was proposed in 1995 [40,41]. Possible statistically significant trends in sample data $\left(x_{1}, x_{2}, \ldots, x_{n}\right)$ are examined using the following procedures:

(1) Compute the lag-1 serial correlation coefficient (designated by $r_{1}$ ). The lag-1 serial correlation coefficient of the sample data $x_{i}$ can be computed by $[42,43]$ :

$$
r_{1}=\frac{\sum_{i=1}^{n-1}\left(x_{i}-\bar{x}\right)\left(x_{i+1}-\bar{x}\right)}{\sum_{i=1}^{n}\left(x_{i}-\bar{x}\right)^{2}}
$$

where $\bar{x}=\sum_{i=1}^{n} x_{i}$ is the overall mean.

(2) If the calculated $r_{1}$ is not significant at the $5 \%$ level, then the Mann-Kendall test is applied to the original values of the time series.

(3) If the calculated $r_{1}$ value is significant prior to the application of the Mann-Kendall test, then the "pre-whitened" time series may be obtained as $\left(x_{2}-r_{1} x_{1}, x_{3}-r_{1} x_{2}, \ldots x_{n} r_{1} x_{n}-1\right)$.

Following $[42,44]$, the probability limits on the correlogram of an independent series are:

$$
r_{1}=\left\{\begin{array}{c}
(-1+1.645 \sqrt{n-2}) /(n-1), \text { one sided } \\
(-1 \pm 1.96 \sqrt{n-2}) /(n-1), \text { two sided }
\end{array}\right.
$$

where $\mathrm{n}$ is the sample size.

Several researchers have applied these non-parametric methods to remote sensing applications [13,45-47], yet this is still questionable (i.e., not removing serial correlation from the series). 
In this study, the Mann-Kendall and Sen's slope estimator for the long time series FVC were calculated on a pixel-by-pixel basis using the "pre-whiten" method first.

\section{Results}

\subsection{Values of $N D V I_{\text {vegi }}$ and $N D V I_{\text {soilj }}$}

The values of GIMMS NDVI ${ }_{\text {vegi }}$ and $\mathrm{NDVI}_{\text {soilj }}$ used in Equation (4) are depicted in Table 1. Deciduous broadleaf forests have the largest value, 0.95 , whereas the grasslands have the smallest value, 0.62 . The values of $\mathrm{NDVI}_{\text {soil }}$ are distributed between 0.08 and 0.34 with a mean value of 0.21 .

\subsection{Evaluation of Global FVC}

Monthly FVCs in China from 2000 to 2011 were computed with MOD13A3 1-km NDVI data, which were used to evaluate the robustness of the modified model and the accuracy of our results. The method used to compute MODIS FVC in China is the same as global FVC, but we used the corresponding year's land cover data (MCD12Q1), which considered land cover type change during different years. Land cover types have been classified into three major forms: forest, grassland and cropland. Time series and scatter plots between GIMMS FVC and MODIS FVC are depicted in Figures 1 and 2.

To further validate the reliability of the GIMMS FVC, we used VALERI images to make a comparison analysis. Most VALERI images are around $3000 \mathrm{~m} \times 3000 \mathrm{~m}$, which is much smaller than GIMMS FVC pixels. Therefore, we choose 18 sites, where the corresponding GIMMS FVC pixels had only one vegetation cover. Scatter plots between GIMMS FVC and VALERI FVC are depicted in Figure 3.

Figure 1. Time series of monthly GIMMS and MODIS fractional vegetation cover (FVC) (2000-2011) for selected regions. GIMMS time series FVC is depicted in black and MODIS FVC in grey.

(1.0


Figure 2. The corresponding scatter plots, including the regression slope, intercept and correlation coefficient between monthly GIMMS FVC and MODIS FVC 2000-2011.
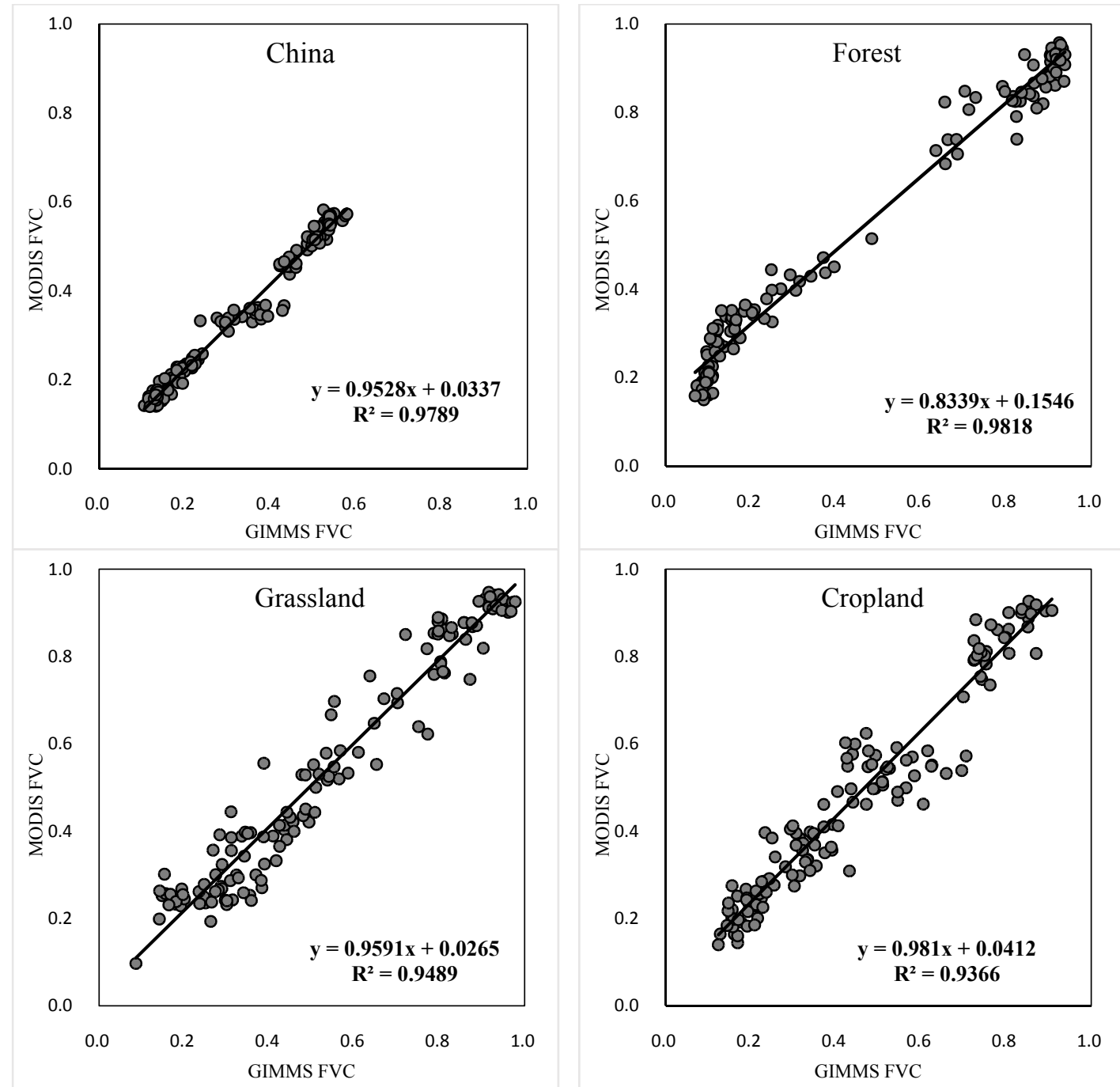

Figure 3. The corresponding scatter plots, including the regression slope, intercept and correlation coefficient between GIMMS FVC and VALERI FVC.

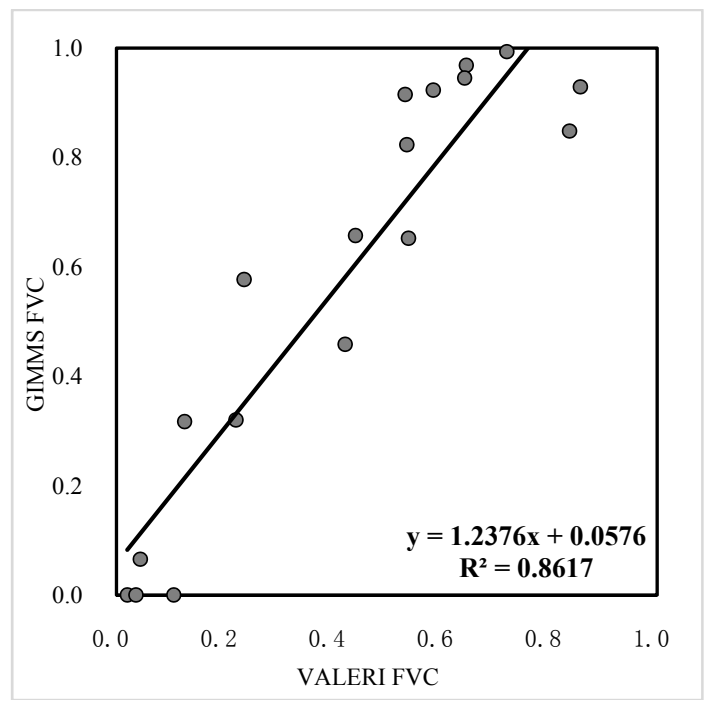


Table 2. Results for the average of the GIMMS $\mathrm{FVC}_{\max }$ and $\mathrm{FVC}_{\text {mean }}$ 1982-2011 images for all the continents. Permanent land snow and ice with limited or no vegetation growth are masked (PSI, permanent snow and ice).

\begin{tabular}{|c|c|c|c|c|c|c|c|c|c|c|c|c|c|c|}
\hline \multirow{2}{*}{$\begin{array}{c}\text { Number of } \\
\text { Observations }\end{array}$} & \multicolumn{7}{|c|}{ Annual Maximum Mean Observations for Pixels 1982-2011 } & \multicolumn{7}{|c|}{ Annual Mean Observations for Pixels 1982-2011 } \\
\hline & Africa & Asia & Europe & $\begin{array}{c}\text { North } \\
\text { America }\end{array}$ & Oceania & $\begin{array}{c}\text { South } \\
\text { America }\end{array}$ & Global & Africa & Asia & Europe & $\begin{array}{c}\text { North } \\
\text { America }\end{array}$ & Oceania & $\begin{array}{c}\text { South } \\
\text { America }\end{array}$ & Global \\
\hline $\begin{array}{l}\text { Total pixels (n) } \\
\text { excluding PSI }\end{array}$ & 365,609 & 767,248 & 201,434 & 433,945 & 110,582 & 221,833 & $2,100,491$ & 365,609 & 767,248 & 201,434 & 433,945 & 110,582 & 221,833 & $2,100,491$ \\
\hline $0.0-0.2 \mathrm{FVC}(\%)$ & 38.20 & 18.50 & 1.75 & 13.06 & 24.69 & 7.71 & 18.39 & 43.70 & 22.30 & 2.29 & 17.06 & 39.55 & 10.81 & 22.72 \\
\hline $0.2-0.4$ FVC $(\%)$ & 4.99 & 4.93 & 1.04 & 7.98 & 22.01 & 4.08 & 6.01 & 11.96 & 12.63 & 4.51 & 13.72 & 20.65 & 5.14 & 11.59 \\
\hline $0.4-0.6$ FVC $(\%)$ & 6.94 & 8.25 & 2.57 & 9.17 & 10.00 & 3.16 & 7.22 & 16.91 & 37.45 & 55.00 & 43.03 & 18.17 & 10.79 & 32.88 \\
\hline $0.6-0.8$ FVC $(\%)$ & 11.18 & 20.41 & 8.84 & 19.34 & 15.36 & 7.43 & 15.84 & 22.40 & 23.70 & 34.48 & 22.56 & 10.70 & 41.90 & 25.51 \\
\hline $0.8-1.0$ FVC $(\%)$ & 38.69 & 47.91 & 85.79 & 50.44 & 27.94 & 77.62 & 52.55 & 5.02 & 3.92 & 3.72 & 3.63 & 10.92 & 31.36 & 7.30 \\
\hline
\end{tabular}

Table 3. Results for the average of the GIMMS FVC ${ }_{\max }$ and $\mathrm{FVC}_{\text {mean }}$ 1982-2011 images for all temperature zones in the world. Permanent land snow and ice with limited or no vegetation growth are masked (PSI, permanent snow and ice).

\begin{tabular}{|c|c|c|c|c|c|c|c|c|}
\hline \multirow[b]{2}{*}{$\begin{array}{c}\text { Number of } \\
\text { Observations }\end{array}$} & \multicolumn{4}{|c|}{ Annual Maximum Mean Observations for Pixels 1982-2011 } & \multicolumn{4}{|c|}{ Annual Mean Observations for Pixels 1982-2011 } \\
\hline & $\begin{array}{l}\text { The North } \\
\text { Frigid Zone }\end{array}$ & $\begin{array}{c}\text { The North } \\
\text { Temperate } \\
\text { Zone } \\
\end{array}$ & $\begin{array}{c}\text { The Torrid } \\
\text { Zone }\end{array}$ & $\begin{array}{c}\text { The South } \\
\text { Temperate } \\
\text { Zone } \\
\end{array}$ & $\begin{array}{c}\text { The North } \\
\text { Frigid Zone }\end{array}$ & $\begin{array}{c}\text { The North } \\
\text { Temperate Zone }\end{array}$ & $\begin{array}{c}\text { The Torrid } \\
\text { Zone }\end{array}$ & $\begin{array}{c}\text { The South } \\
\text { Temperate Zone }\end{array}$ \\
\hline $\begin{array}{l}\text { Total pixels(n) } \\
\text { excluding PSI }\end{array}$ & 210,781 & $1,140,117$ & 597,150 & 152,443 & 210,781 & $1,140,117$ & 597,150 & 152,443 \\
\hline $0.0-0.2 \mathrm{FVC}(\%)$ & 21.59 & 17.22 & 17.44 & 26.35 & 25.03 & 20.69 & 21.95 & 37.72 \\
\hline $0.2-0.4 \mathrm{FVC}(\%)$ & 9.06 & 4.82 & 4.59 & 16.18 & 14.02 & 11.14 & 10.79 & 14.75 \\
\hline $0.4-0.6 \mathrm{FVC}(\%)$ & 12.92 & 6.86 & 5.79 & 7.69 & 44.17 & 41.71 & 16.99 & 13.45 \\
\hline $0.6-0.8 \mathrm{FVC}(\%)$ & 37.75 & 14.68 & 11.64 & 10.62 & 16.07 & 24.47 & 33.25 & 16.00 \\
\hline $0.8-1.0 \mathrm{FVC}(\%)$ & 18.68 & 56.41 & 60.54 & 39.15 & 0.71 & 1.99 & 17.01 & 18.07 \\
\hline
\end{tabular}


Table 4. Trend statistics for the GIMMS FVC analysis 1982-2011 $(p=0.05)$ for all the continents. Permanent land snow and ice with limited or no vegetation growth are masked (PSI, permanent snow, ice and barren land).

\begin{tabular}{|c|c|c|c|c|c|c|c|c|c|c|c|c|c|c|}
\hline \multirow[b]{2}{*}{ Number of Observations } & \multicolumn{7}{|c|}{ Annual Maximum Observations for Pixels 1982-2011 } & \multicolumn{7}{|c|}{ Annual Mean Observations for Pixels 1982-2011 } \\
\hline & Africa & Asia & Europe & $\begin{array}{c}\text { North } \\
\text { America }\end{array}$ & Oceania & $\begin{array}{c}\text { South } \\
\text { America }\end{array}$ & Global & Africa & Asia & Europe & $\begin{array}{c}\text { North } \\
\text { America }\end{array}$ & Oceania & $\begin{array}{c}\text { South } \\
\text { America }\end{array}$ & Global \\
\hline Total pixels (n) excluding PSI & 365,609 & 767,248 & 201,434 & 433,945 & 110,582 & 221,833 & $2,100,491$ & 365,609 & 767,248 & 201,434 & 433,945 & 110,582 & 221,833 & $2,100,491$ \\
\hline $\mathrm{k}<-0.01(\%)$ & 0.00 & 0.00 & 0.00 & 0.00 & 0.00 & 0.00 & 0.00 & 0.00 & 0.00 & 0.00 & 0.00 & 0.00 & 0.00 & 0.00 \\
\hline$-0.01<\mathrm{k}<-0.005(\%)$ & 0.06 & 0.10 & 0.10 & 0.12 & 0.05 & 0.14 & 0.10 & 0.00 & 0.05 & 0.02 & 0.02 & 0.00 & 0.01 & 0.02 \\
\hline$-0.005<\mathrm{k}<-0.002(\%)$ & 0.34 & 1.16 & 0.89 & 2.03 & 0.23 & 0.94 & 1.10 & 0.55 & 1.21 & 0.54 & 1.90 & 0.38 & 1.63 & 1.17 \\
\hline$-0.002<\mathrm{k}<-0.001(\%)$ & 0.17 & 0.66 & 0.31 & 1.16 & 0.08 & 0.51 & 0.60 & 0.89 & 0.32 & 0.10 & 2.89 & 0.42 & 1.74 & 1.09 \\
\hline$-0.001<\mathrm{k}<0.001(\%)$ & 3.02 & 1.97 & 3.65 & 1.39 & 0.61 & 2.20 & 2.15 & 2.78 & 1.24 & 0.07 & 0.77 & 1.46 & 0.65 & 1.25 \\
\hline $0.001<\mathrm{k}<0.002(\%)$ & 2.59 & 2.68 & 4.44 & 4.13 & 4.35 & 4.58 & 3.42 & 6.12 & 3.69 & 7.17 & 6.47 & 5.26 & 6.29 & 5.38 \\
\hline $0.002<\mathrm{k}<0.005(\%)$ & 9.36 & 8.51 & 6.50 & 10.32 & 9.48 & 9.26 & 8.97 & 5.87 & 11.55 & 14.46 & 6.11 & 4.01 & 6.93 & 8.83 \\
\hline $0.005<\mathrm{k}<0.01(\%)$ & 2.00 & 1.14 & 0.68 & 0.58 & 2.54 & 0.40 & 1.13 & 0.16 & 0.24 & 0.11 & 0.03 & 0.38 & 0.01 & 0.15 \\
\hline $\mathrm{k}>0.01(\%)$ & 0.06 & 0.03 & 0.03 & 0.00 & 0.28 & 0.00 & 0.04 & 0.00 & 0.00 & 0.00 & 0.00 & 0.01 & 0.00 & 0.00 \\
\hline
\end{tabular}

Table 5. Trend statistics for the GIMMS FVC Mann-Kendall analysis 1982-2011 $(p=0.05)$ for all temperature zones in the world.

\begin{tabular}{|c|c|c|c|c|c|c|c|c|}
\hline \multirow[b]{2}{*}{ Number of Observations } & \multicolumn{4}{|c|}{ Annual Maximum Observations for Pixels 1982-2011 } & \multicolumn{4}{|c|}{ Annual Mean Observations for Pixels 1982-2011 } \\
\hline & $\begin{array}{c}\text { The North } \\
\text { Frigid Zone }\end{array}$ & $\begin{array}{c}\text { The North } \\
\text { Temperate Zone }\end{array}$ & $\begin{array}{c}\text { The Torrid } \\
\text { Zone } \\
\end{array}$ & $\begin{array}{c}\text { The South } \\
\text { Temperate Zone }\end{array}$ & $\begin{array}{c}\text { The North } \\
\text { Frigid Zone }\end{array}$ & $\begin{array}{c}\text { The North } \\
\text { Temperate Zone }\end{array}$ & $\begin{array}{c}\text { The Torrid } \\
\text { Zone } \\
\end{array}$ & $\begin{array}{c}\text { The South } \\
\text { Temperate Zone }\end{array}$ \\
\hline Total pixels (n) excluding PSI & 210,781 & $1,140,117$ & 597,150 & 152,443 & 210,781 & $1,140,117$ & 597,150 & 152,443 \\
\hline $\mathrm{k}<-0.01(\%)$ & 0.00 & 0.00 & 0.00 & 0.01 & 0.00 & 0.00 & 0.00 & 0.00 \\
\hline$-0.01<\mathrm{k}<-0.005(\%)$ & 0.08 & 0.11 & 0.07 & 0.18 & 0.06 & 0.03 & 0.01 & 0.00 \\
\hline$-0.005<\mathrm{k}<-0.002(\%)$ & 2.00 & 1.29 & 0.42 & 1.06 & 2.25 & 1.13 & 0.90 & 1.09 \\
\hline$-0.002<\mathrm{k}<-0.001(\%)$ & 0.59 & 0.81 & 0.25 & 0.40 & 0.37 & 1.19 & 0.96 & 1.75 \\
\hline$-0.001<\mathrm{k}<0.001(\%)$ & 0.25 & 2.44 & 2.52 & 1.11 & 0.12 & 1.33 & 1.40 & 1.56 \\
\hline $0.001<\mathrm{k}<0.002(\%)$ & 4.89 & 3.10 & 3.51 & 3.43 & 4.51 & 5.01 & 6.62 & 4.51 \\
\hline $0.002<\mathrm{k}<0.005(\%)$ & 19.96 & 6.55 & 10.10 & 7.49 & 15.61 & 9.16 & 7.48 & 2.32 \\
\hline $0.005<\mathrm{k}<0.01(\%)$ & 0.32 & 0.84 & 1.87 & 1.47 & 0.09 & 0.18 & 0.14 & 0.11 \\
\hline $\mathrm{K}>0.01(\%)$ & 0.00 & 0.03 & 0.08 & 0.05 & 0.00 & 0.00 & 0.00 & 0.00 \\
\hline
\end{tabular}




\subsection{Global Fractional Vegetation Cover}

After calculating the global monthly FVC from 1982 to 2011 for each pixel in an image, we computed the monthly area mean FVC of all the continents in the world. Monthly FVC change curves from 1982 to 2011 are shown in Figure 4.

Figure 4. Monthly FVC changes of the six continents in the world from 1982 to 2011. (A-G) Global, Africa, Asia, Europe, North America, Oceania and South America monthly FVC changes, respectively.

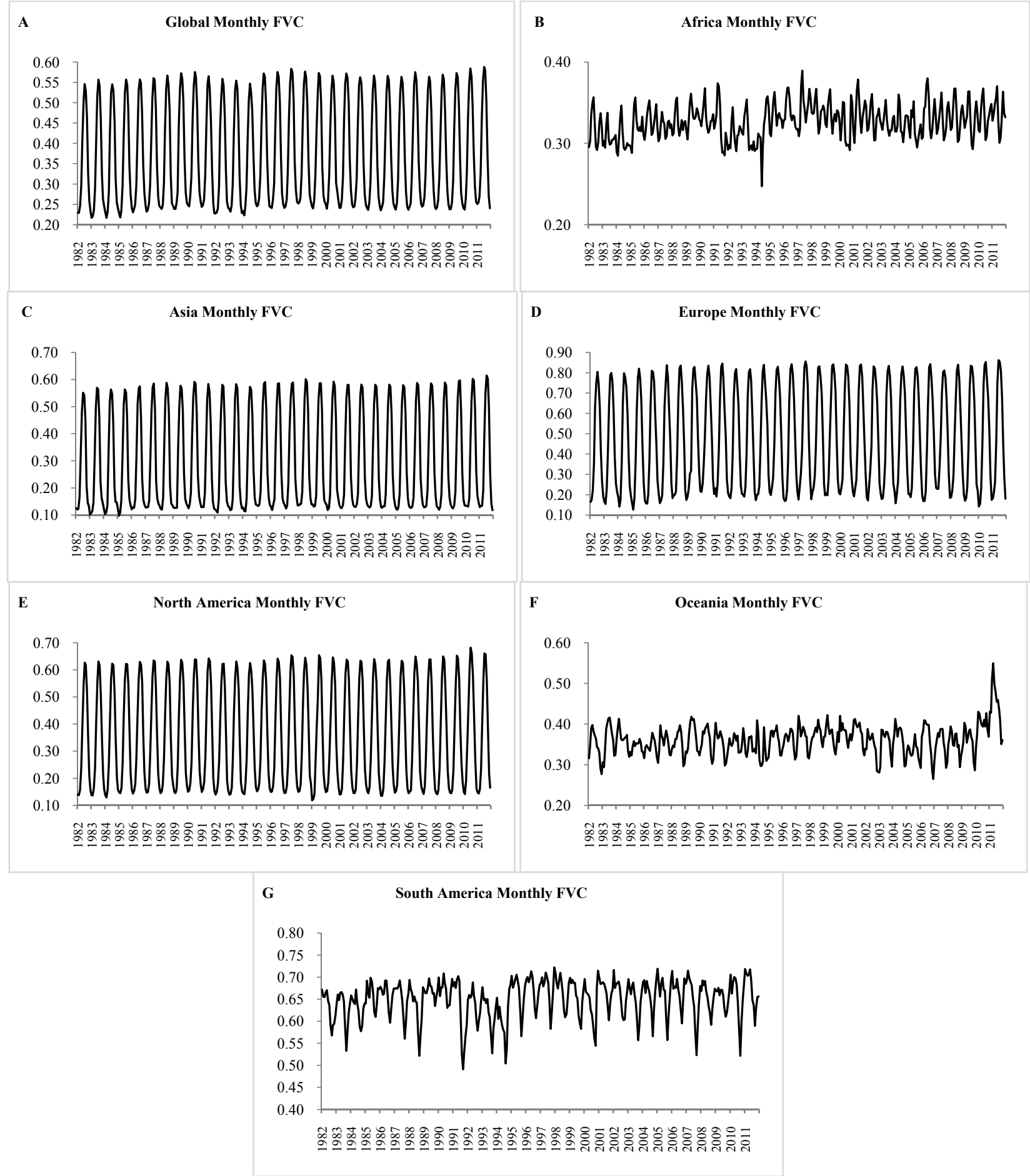


Figure 5. The annual maximum and mean FVC of the seven continents of the world from 1982 to 2011. (A-G) Global, Africa, Asia, Europe, North America, Oceania and South America yearly FVC (\%) change, respectively. The black lines represent the annual maximum value and grey the annual mean value.
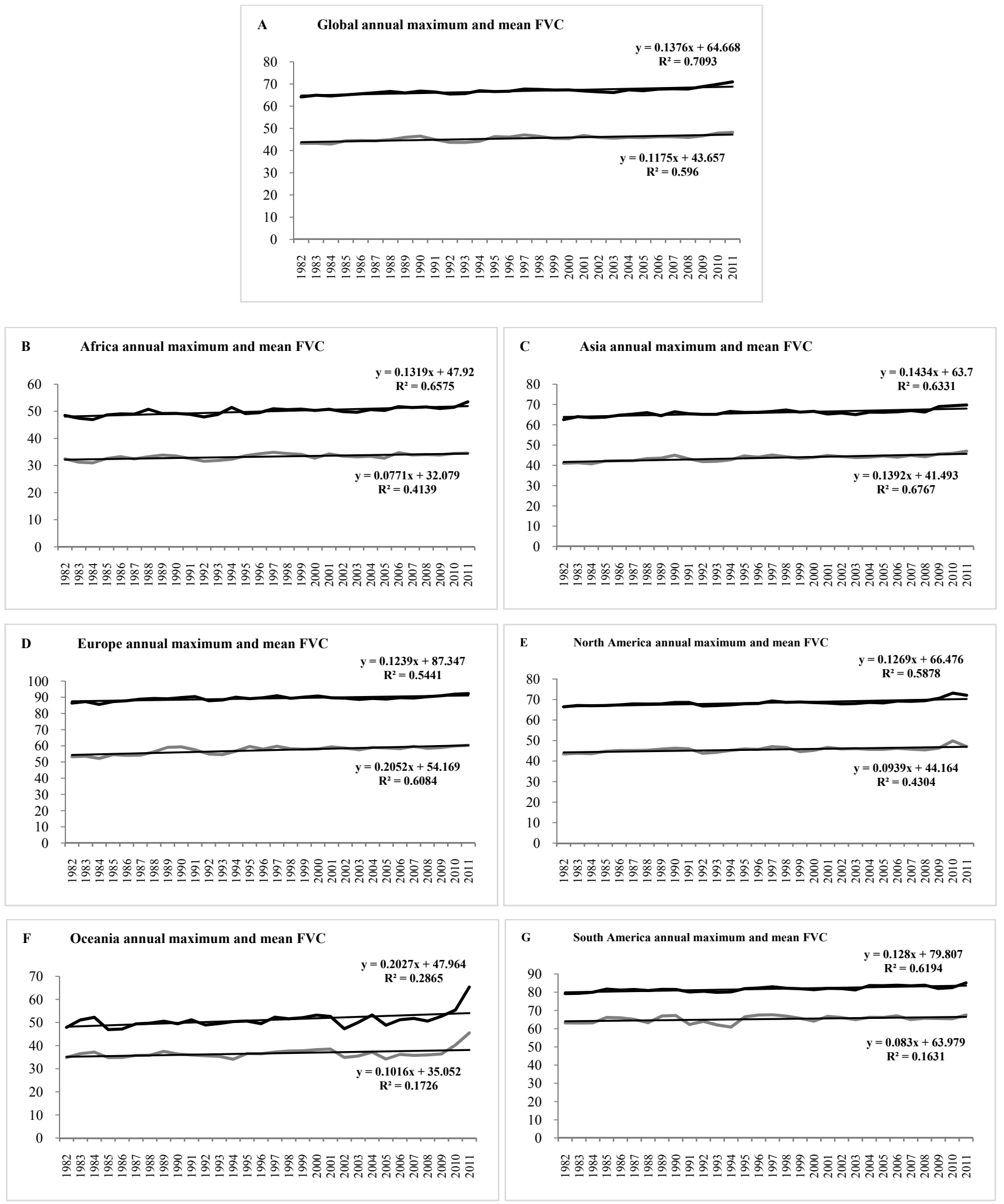
We also calculated annual maximum and mean FVC image on a pixel-by-pixel basis from 1982 to 2011. The annual mean image averaged pixels contained an FVC greater than zero in a year, which eliminates the influence of snow and ice in the high latitudes of the northern hemisphere. The annual area average of maximum and mean FVC of the seven continents of the world, besides Antarctica, was then computed and is shown in Figure 5.

Figure 6. (A) Annual maximum mean FVC image computed from 1982 to 2011. (B) Annual mean FVC image computed from 1982 to 2011.

\section{(A) Annual Maximum Mean Global GIMMS FVC 1982-2011}

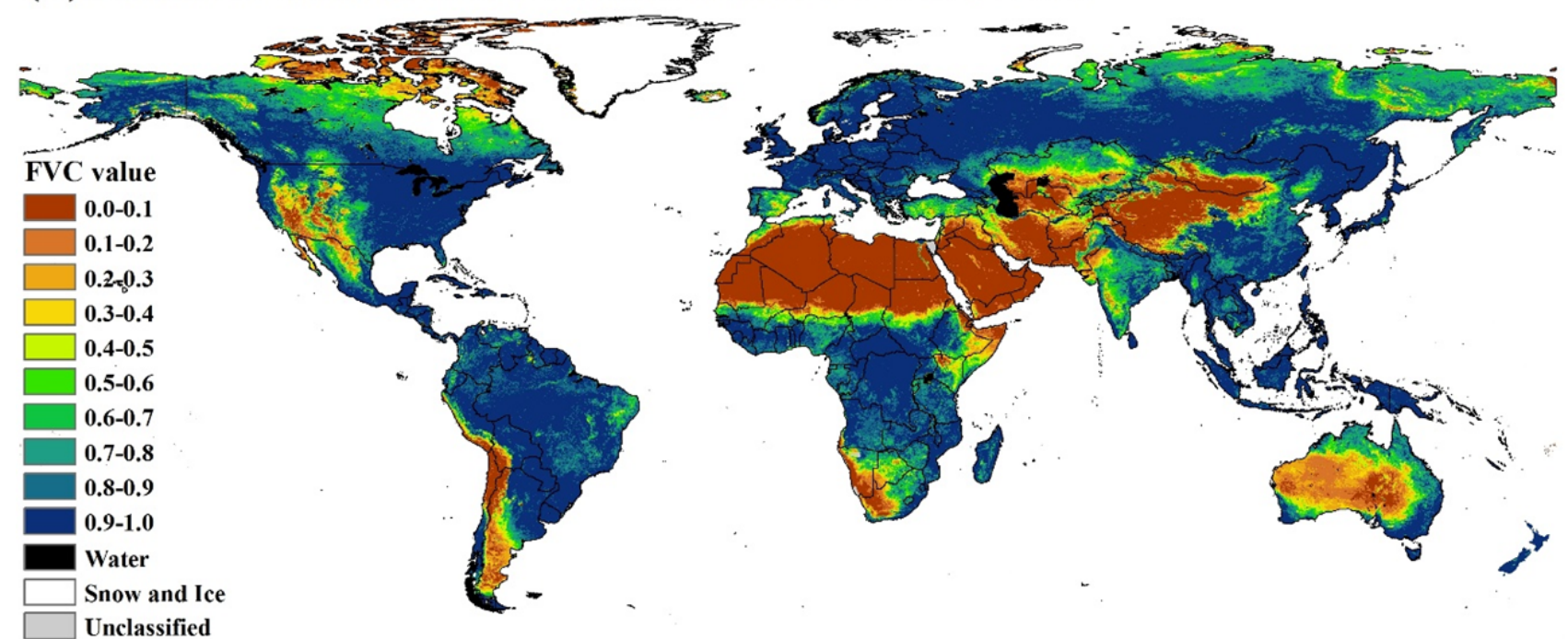

\section{(B) Annual Mean Mean Global GIMMS FVC 1982-2011}

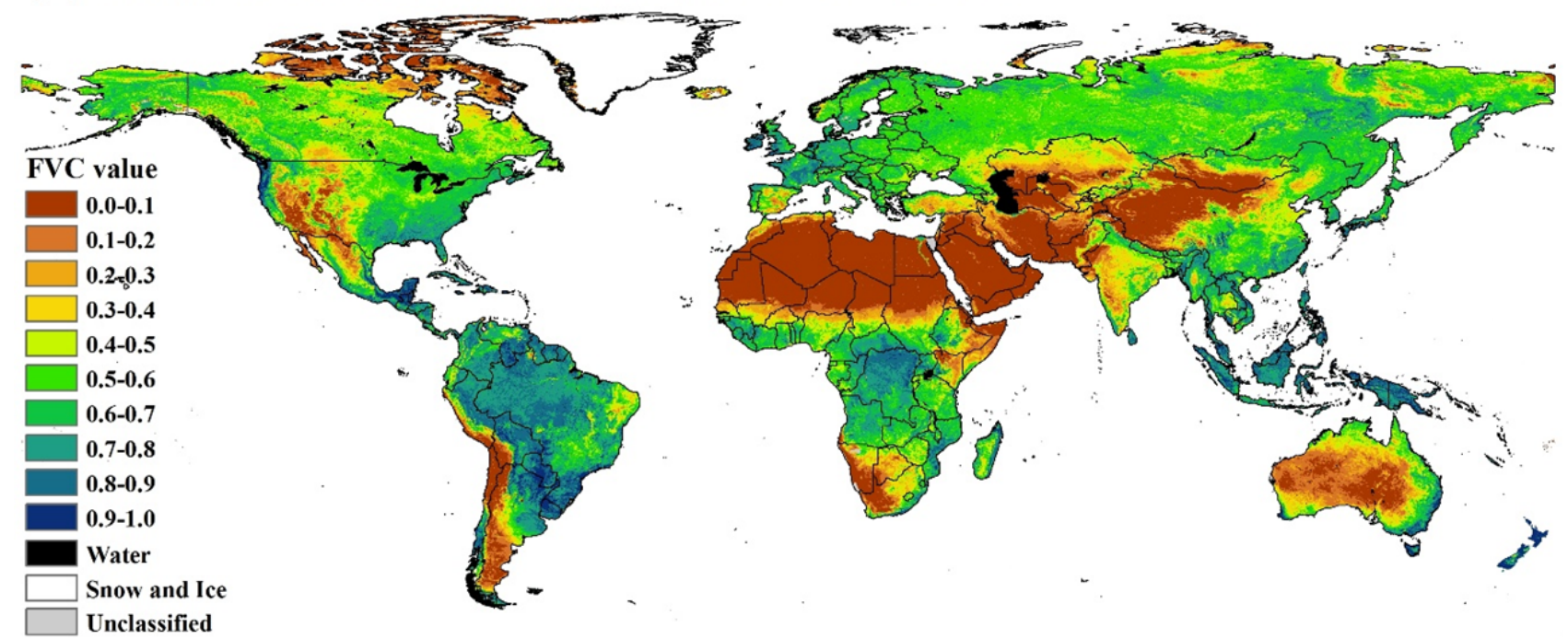

The average annual maximum FVC image and annual mean FVC image computed from 1982 to 2011 for the pixels are shown in Figure 6. The figure shows the status of the global maximum and mean FVC. The North Frigid Zone, The North Temperate Zone, The Torrid Zone and The South Temperate Zone statistics for the average of GIMMS FVC ${ }_{\max }$ and $\mathrm{FVC}_{\text {mean }}$ 1982-2011 images were computed (the total number of pixels and in \%) and are in Tables 2 and 3 , respectively. 
The above results of the global FVC masked permanent snow and ice land with limited or no vegetation growth (defined as permanent snow and ice (PSI)), as there is no GIMMS NDVI data information in these areas.

\subsection{Trend Analysis of Annual $F V C_{\text {max }}$ and $F V C_{\text {mean }}$}

The annual $\mathrm{FVC}_{\max }$ and $\mathrm{FVC}_{\text {mean }}$ significant trends computed by the Mann-Kendall method and Sen's slope estimator in 1982-2011 GIMMS FVC are shown in Figure 7. The statistics of pixels with positive and negative $\mathrm{k}$ values for the 0.05 significance level are calculated for each continent and each temperature zone (total number of pixel and in percent) in Tables 4 and 5.

\section{Discussion}

\subsection{Global FVC Evaluation}

The FVC time series and scatterplot (Figures 1 and 2) show that 10-km GIMMS FVC have very high consistency with 1-km MODIS FVC, which proves the high robustness of the modified dimidiate pixel model. It should be noted that the $\mathrm{R}^{2}$ value is close to 1.0 from an average of pixels in the selected regions. The reason for the good match, except the robustness of the modified model, is the result of the noise introduced from cloud cover influence in the regions to be reduced by the spatial averaging. Figure 3 shows that GIMMS FVC matches nicely to VALERI FVC with an $\mathrm{R}^{2}$ of 0.86 , while GIMMS FVC have some overestimation. This may be induced by the uncertainty of the two datasets (system error and model error of GIMMS FVC, observation error and algorithmic error of VALERI FVC and scale matching problem). In general, the produced GIMMS FVC shows strong robustness, good reliability and high accuracy, and the global FVC evaluation will be based on this results.

\subsection{Global Fractional Vegetation Cover (FVC)}

It can be inferred from Figure 4 that the global FVC change is between 0.20 and 0.60 in a year with obvious seasonal variability. There are, however, remarkable differences between the northern hemisphere and the southern hemisphere. The northern hemisphere has from $50 \%$ to $70 \%$ seasonal FVC change, while the southern hemisphere has from $10 \%$ to $20 \%$ change. Moreover, the northern hemisphere has a much more visible seasonal variability than the southern hemisphere.

\subsubsection{Change of Global GIMMS FVC 1982-2011}

In the northern hemisphere, Asia's FVC in a year varies from 0.1 to 0.6. North America has a similar variation from 0.1 to 0.7 , and Europe expresses greater vegetation coverage than the first two and ranges from 0.1 to 0.85 .

In the southern hemisphere, Africa has a low FVC change from 0.25 to 0.4 in a year. Oceania's FVC is greater than Africa and is approximately 0.25 to 0.45, and South America has the largest FVC in the world from 0.50 to 0.75 .

As depicted in Figure 5, the global annual maximum average FVC is 66.8\% during 1982 and 2011, while the annual mean average FVC is $45.48 \%$. Europe expresses the highest maximum FVC value of 
89.27\%. The second highest value for the annual maximum FVC is from South America with a value of 81.79\%. Thereafter, the average maximum area FVC of North America, Asia, Oceania and Africa in the last 30 years are $68.44 \%, 65.92 \%, 51.11 \%$ and $49.96 \%$, respectively. In all six continents, the annual maximum area FVCs, which are statistically significant at the $p=0.001$ level using the Student's t-test, show an increasing trend, except in Oceania. Global annual maximum and mean FVC growth rates are $0.14 \% / y$ and $0.12 \% / y$, respectively.

\subsubsection{Distribution of Averaged Global FVC 1982-2011}

As depicted in Figure 6A, 52.55\% of the pixels of all of the continents express a high FVC (0.8-1.0), while only $18.39 \%$ of the pixels display a low FVC. There are $7.30 \%$ high FVC pixels and $22.72 \%$ low FVC pixels for all of the continents in the average annual mean FVC image 1982-2011 (Figure 6B). The results stated that more than half of the pixels of the entire world can reach a high FVC in a year, while global mean FVC in a year still maintains medium FVC (0.2-0.8) values of $69.98 \%$.

Europe has the highest value of $85.79 \%$ (Figure 6A), which can reach a high FVC in a year. There are only $3.72 \%$ high FVC pixels in Figure $6 \mathrm{~B}$, which was caused by the large inter-annual variation. This phenomenon also appears in continents in the north hemisphere, which have large differences between a year maximum and a mean image (Asia with its differences of $43.99 \%$ and North America with its differences of $46.81 \%$ ). South America has the highest value of $31.36 \%$ (Figure 6B), whose mean value can reach a high FVC in a year. Oceania has the smallest difference value of $17.02 \%$, while Africa and South America have values of $33.67 \%$ and $46.26 \%$, respectively.

It is the Torrid Zone that has the highest value of $60.54 \%$ (Figure 6A), which can reach a high FVC in a year, while the North Temperate Zone has the highest value of $56.41 \%$ in Figure 5A. Eighteen-point-sixty eight percent of the pixels of the North Frigid Zone can reach a high FVC in a year (Figure 6A), while in Figure 6B, 74.26\% express medium FVC during the growing season in a year. The results indicated that the high FVC pixels decrease with an increase of latitude.

\subsection{GIMMS Annual $F V C_{\max }$ and $F V C_{\text {mean }}$ Trends}

Areas of increasing and decreasing greenness can be observed from both the annual GIMMS FVC $\mathrm{max}_{\text {a }}$ and the GIMMS FVC mean datasets (Figure 7). Meanwhile, the number of pixels with the significant FVC trends $(p=0.05)$ for all of the continents is fairly similar for the GIMMS FVC $_{\max }$ and the GIMMS $\mathrm{FVC}_{\text {mean }}$ datasets. Excluding pixels with slow variation $(-0.001<\mathrm{k}<0.001)$, a significant trend on the $p=0.05$ level was found for $15.36 \%$ of the GIMMS $\mathrm{FVC}_{\max }$ pixels on a global scale (excluding permanent snow and ice) (1.8\% have negative trends and $13.56 \%$ have positive trends), whereas the

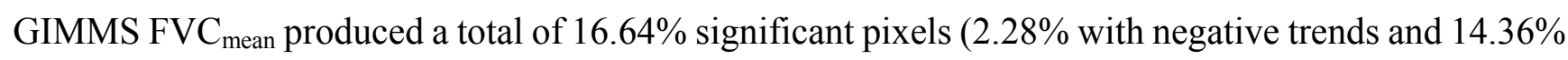
with positive trends).

\subsubsection{Areas of Negative GIMMS FVC Trends}

Both datasets generally show significant negative trends $(p=0.05)$ in Alaska, central Canada, central and southern South America (Argentina), Southern Africa (Angola, Zambia, Botswana and Congo), Northern Europe (Norway, Sweden and Finland), northwestern Russia, Northern Mongolia and 


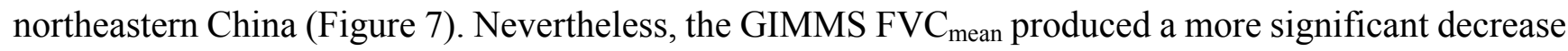
of pixels than the GIMMS FVC ${ }_{\max }$ for all of the continents in Table 4. The most significant decrease is pixels covered by open shrub. There are large differences in the results from South America and North America, with differences of $1.79 \%$ and $1.5 \%$, and small differences in the results from Africa, Asia, Europe and Oceania, with differences of $0.87 \%, 0.34 \%, 0.64 \%$ and $0.44 \%$, respectively. The total differences of global continents are $0.48 \%$.

Significant trends from the $p=0.05$ level, excluding pixels with slow variation $(-0.001<\mathrm{k}<0.001)$, represented $20.21 \%$ of the GIMMS FVC mean pixels in the North Frigid Zone (excluding permanent snow and ice) in Table 5, which was the highest value of all of the temperature zones. The North Temperate Zone, the Torrid Zone and the South Temperate Zone were 14.35\%, 14.24\% and 6.94, respectively.

\subsubsection{Areas of Positive GIMMS FVC Trends}

Results show that each dataset from the GIMMS FVC max $_{\text {and }}$ and the GIMMS FVC $_{\text {mean }}$ produced large-scale greenness of all of the continents (Figure 7). In North America, areas of northern Canada, northern Alaska and America show significant positive trends $(p=0.05)$ of the two datasets. Northern and eastern South America, central and southeastern Africa, Europe (excluding Norway, Sweden and Finland), western and northeastern Russia, India, eastern China, northern Indonesia and northwestern Australia also exhibit significant positive trends $(p=0.05)$ of the GIMMS FVC $_{\max }$ and the GIMMS $\mathrm{FVC}_{\text {mean }}$ datasets. The GIMMS $\mathrm{FVC}_{\text {max }}$ produced similar significant increase of pixels with the GIMMS $\mathrm{FVC}_{\text {mean }}$ for all of the continents, except for Europe, which has differences of $10.09 \%$. There are small differences in the results from Africa, South America, Oceania North America and Asia, with differences of $1.86 \%, 1.01 \%, 6.99 \%, 2.42 \%$ and $3.12 \%$, respectively. Global differences from the continents between the two datasets are $0.8 \%$.

Figure 7. (A) The GIMMS FVC trend for the 0.05 significance level (1982-2011 annual maximum observations for pixels with positive and negative $\mathrm{k}$ ). (B) The GIMMS FVC trend for the 0.05 significance level (1982-2011 annual mean observations for pixels with positive and negative $\mathrm{k}$ ).

\section{(A) Trend of Annual Maximum Global GIMMS FVC 1982-2011}

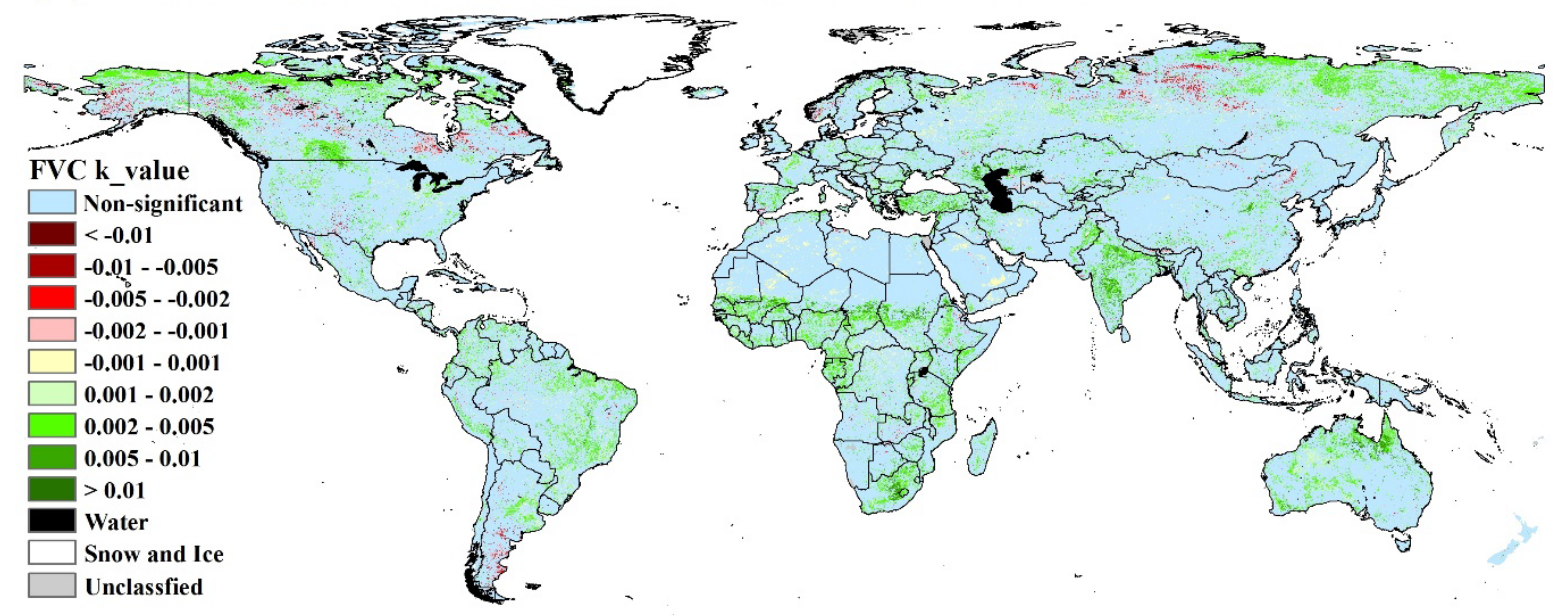


Figure 7. Cont.

\section{(B) Trend of Annual Mean Global GIMMS FVC 1982-2011}

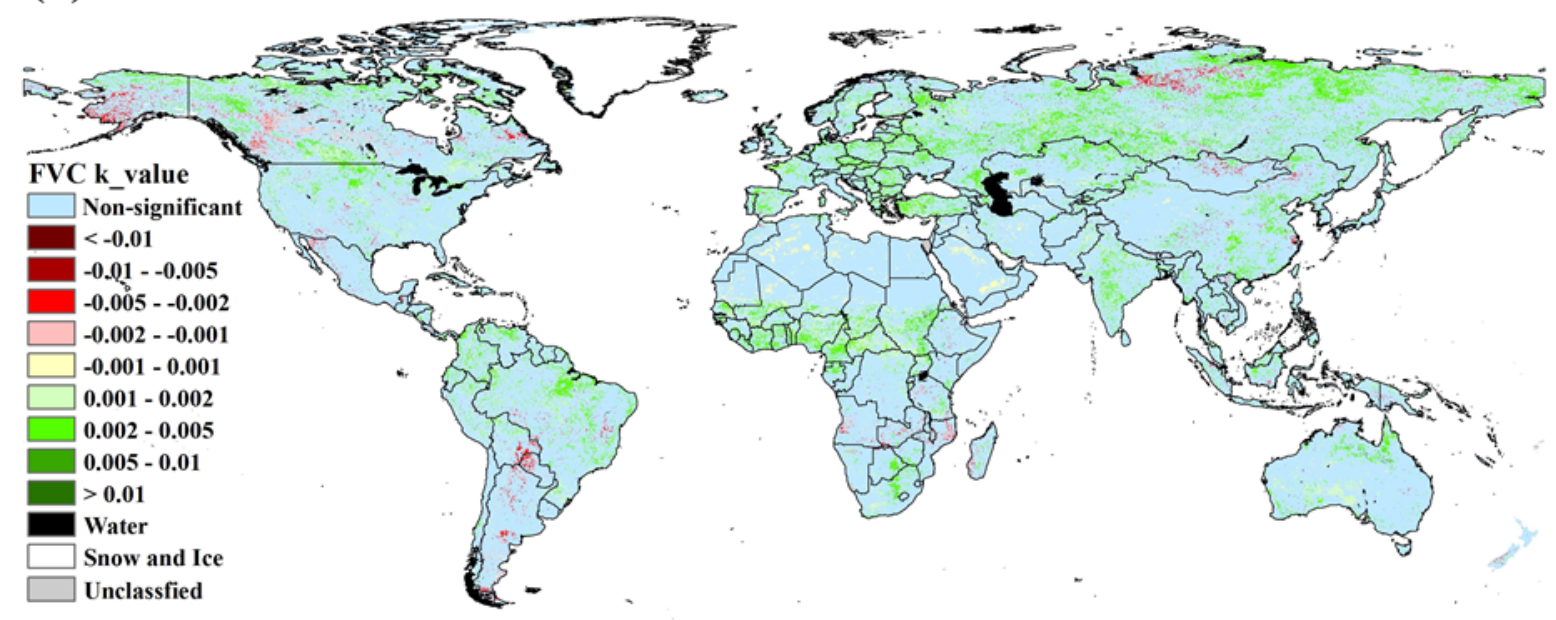

Significant trends of the GIMMS $\mathrm{FVC}_{\max }$ on the $p=0.05$ level is $25.17 \%$ in the North Frigid Zone, the highest value of all the temperature zones. $\mathrm{The}_{\mathrm{FVC}}$ max of pixels in a year represents biomass production and peak photosynthetic activity [48], so the highest FVC of pixels of the North Frigid Zone in a year have increased remarkably in the last 30 years. Arctic summer and winter warming caused sea ice decline [49-51] combined with the effects that triggered albedo decrease [52], NDVI increase [48], massive phytoplankton blooms [53], an advance in the growing season [54] and other ecological consequences [55]. Arctic warming has been linked to observed increases in tundra shrub cover and growth in recent decades based on significant relationships between deciduous shrub growth/biomass and temperature [56]. The result in our study also said that the dramatic increases in the $\mathrm{FVC}_{\max }$ in the North Frigid Zone might be a consequence of temperature amplification, sea ice loss and an advance in the growing season.

The Earth's climate has warmed by approximately $0.6{ }^{\circ} \mathrm{C}$ over the past 100 years with two main periods of warming, between 1910 and 1945 and from 1976 to the present [57]. The rate of warming during the latter period has been approximately twice that of the first and, thus, greater than at any other time during the last 1,000 years [58]. Previous research reported that global accelerating warming has induced longer growing seasons of temperate vegetation in the Northern Hemisphere in the last 30 years [59]. The climate driven factor of temperate vegetation in North Hemisphere is mainly temperature [60], which, to a large extent, should be the major reason for vegetation greenness at northern middle and high latitudes. Global warming can accelerate land surface drying and cause more atmospheric water vapor. Additional atmospheric water vapor increases the risk of heavy precipitation events [61]. Because of the region total precipitation remaining constant, stronger precipitation events will decrease days with cloudiness and increase the area solar radiation amount. The driving climate factor is radiation in tropical forests, as in Nemani's study [60], so it will induce vegetation greenness in these regions. Vegetation variations are influenced by many factors, such as climate conditions, human activities, land cover changes, and so on. A deeper relationship (forcings and feedbacks) between these factors and vegetation need further research. 


\section{Conclusions}

Based on the GIMMS NDVI global coverage dataset, the USGS global land cover characteristics data and the HWSD soil type dataset, we analyzed the global fractional vegetation cover and FVC trend in the last 30 years with the modified dimidiate pixel model. The evaluation of the robustness and the accuracy of the GIMMS FVC with MODIS FVC and VALERI FVC show high reliability. We estimated the differences of areal FVC changes and distributions between six of the continents of the world and four temperature zones. The results indicated that all continents (except Oceania) changed in annual $\mathrm{FVC}_{\max }$ and $\mathrm{FVC}_{\text {mean }}$, showing significant increases based on a statistical significance level of $p=0.001$ using the Student's t-test. The global annual maximum and mean FVC growth rates are $0.14 \% / y$ and $0.12 \% / y$, respectively. In addition, the FVC trend analysis used the Mann-Kendall method, and Sen's slope

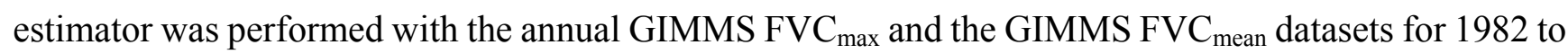
2011. The most significant changes are in pixels turning green for the last three decades $(1.8 \%$ of pixels had negative trends and $13.56 \%$ had positive trends of the annual $\mathrm{FVC}_{\max }$ and $2.28 \%$ have negative trends and $14.36 \%$ have positive trends for the annual $\mathrm{FVC}_{\text {mean }}$, based on the $p=0.05$ level). These findings for global FVC not only show the magnitudes of every pixel and continent, but also can reveal significant increases or decreases in area in the world. Future studies will explore the deeper relationship between the climate factors and vegetation.

\section{Acknowledgments}

This work was supported by the High Technology Research and Development Program of China (Grant NO. 2013AA122801) and the National Natural Science Foundation of China (Grant NO. 41301353). The authors wish to thank the anonymous referees for their valuable comments. The authors also acknowledge the Global Inventory Monitoring and Modeling Systems (GIMMS) group, USGS global land cover characteristics database project, the Harmonized World Soil Database (HWSD) project and the Validation of Land European Remote sensing Instruments (VALERI) project for the provision of research databases used in this study.

\section{Author Contributions}

Xiang Zhao, Donghai Wu and Tao Zhou designed the research. Donghai Wu and Hao Wu performed analysis and calculations. Donghai $\mathrm{Wu}$ and Xiang Zhao drafted the paper writing and revision. Bijian Tang and Wenqian Zhao provided the remotely sensed NDVI data and contributed to the text. Kun Jia provided the FVC validation data of the VALERI project and contributed to the text.

\section{Conflicts of Interest}

The authors declare no conflict of interest. 


\section{References}

1. Sellers, P.; Schimel, D. Remote sensing of the land biosphere and biogeochemistry in the EOS era: Science priorities, methods and implementation-EOS land biosphere and biogeochemical cycles panels. Glob. Planet. Chang. 1993, 7, 279-297.

2. Gutman, G.; Ignatov, A. The derivation of the green vegetation fraction from NOAA/AVHRR data for use in numerical weather prediction models. Int. J. Remote Sens. 1998, 19, 1533-1543.

3. Jiapaer, G.; Chen, X.; Bao, A. A comparison of methods for estimating fractional vegetation cover in arid regions. Agric. For Meteorol. 2011, 151, 1698-1710.

4. Yue, Y.; Wang, K.; Zhang, B.; Jiao, Q.; Liu, B.; Zhang, M. Remote sensing of fractional cover of vegetation and exposed bedrock for karst rocky desertification assessment. Proced. Environ. Sci. 2012, 13, 847-853.

5. Liang, S.; Li, X.; Wang, J. Advanced Remote Sensing; Academic Press: Oxford, UK, 2012.

6. Mu, X.; Liu, Y.; Yan, G.; Yao, Y. Fractional Vegetation Cover Retrieval Using Multi-Spatial Resolution Data and Plant Growth Model. In Proceedings of 2010 IEEE International Geoscience and Remote Sensing Symposium (IGARSS), Honolulu, HI, USA, 25-30 July 2010; pp. 241-244.

7. Montandon, L.M.; Small, E.E. The impact of soil reflectance on the quantification of the green vegetation fraction from NDVI. Remote Sens. Environ. 2008, 112, 1835-1845.

8. Zhou, Z.C.; Shangguan, Z.P.; Zhao, D. Modeling vegetation coverage and soil erosion in the Loess Plateau Area of China. Ecol. Modell. 2006, 198, 263-268.

9. Zeng, X.; Dickinson, R.E; Walker, A.; Shaikh, M.; DeFries, R.S.; Qi, J. Derivation and evaluation of global 1-km fractional vegetation cover data for land modeling. J. Appl. Meteorol. 2000, 39, $826-839$.

10. Zeng, X.; Rao, P.; DeFries, R.S.; Hansen, M.C. Interannual variability and decadal trend of global fractional vegetation cover from 1982 to 2000. J. Appl. Meteorol. 2003, 42, 1525-1530.

11. Dai, Y.; Zeng, X.; Dickinson, R.E.; Baker, I.; Bonan, G.B.; Bosilovich, M.G.; Denning, A.S.; Dirmeyer, P.A.; Houser, P.R.; Niu, G. The common land model. Bull. Am. Meteorol. Soc. 2003, 84, 1013-1023.

12. Zhou, L.; Tucker, C.J.; Kaufmann, R.K.; Slayback, D.; Shabanov, N.V.; Myneni, R.B. Variations in northern vegetation activity inferred from satellite data of vegetation index during 1981 to 1999. J. Geophys. Res.: Atmos. 2001, 106, 20069-20083.

13. Fensholt, R.; Proud, S.R. Evaluation of earth observation based global long term vegetation trends-comparing gimms and modis global ndvi time series. Remote Sens. Environ. 2012, 119, 131-147.

14. Tucker, C.J.; Pinzon, J.E.; Brown, M.E.; Slayback, D.A.; Pak, E.W.; Mahoney, R.; Vermote, E.F.; El Saleous, N. An extended AVHRR 8-km NDVI dataset compatible with MODIS and SPOT vegetation NDVI data. Int. J. Remote Sens. 2005, 26, 4485-4498.

15. Pinzon, J.E.; Brown, M.E.; Tucker, C.J. Satellite Time Series Correction of Orbital Drift Artifacts Using Empirical Mode Decomposition. In Hilbert-Huang Transform: Introduction and Applications; World Scientific: Singapore, 2005; pp. 167-186. 
16. Brown, M.E.; Pinzon, J.E.; Didan, K.; Morisette, J.T.; Tucker, C.J. Evaluation of the consistency of long-term NDVI time series derived from AVHRR, SPOT-vegetation, SeaWiFS, MODIS, and Landsat ETM+ sensors. IEEE Trans. Geosci. Remote Sens. 2006, 44, 1787-1793.

17. Pinheiro, A.C.; Privette, J.L.; Mahoney, R.; Tucker, C.J. Directional effects in a daily AVHRR land surface temperature dataset over Africa. IEEE Trans. Geosci. Remote Sens. 2004, 42, 1941-1954.

18. Holben, B.N. Characteristics of maximum-value composite images from temporal AVHRR data. Int. J. Remote Sens. 1986, 7, 1417-1434.

19. Huete, A.; Justice, C.; van Leeuwen, W. MODIS Vegetation Index (MOD13); Algorithm Theoretical Basis Document; 1999. Available online: http://modis.gsfc.nasa.gov/data/atbd/atbd_mod13.pdf (accessed on 23 April 2014).

20. van Leeuwen, W.J.D.; Huete, A.R.; Laing, T.W. Modis vegetation index compositing approach: A prototype with AVHRR data. Remote Sens. Environ. 1999, 69, 264-280.

21. Loveland, T.; Reed, B.; Brown, J.; Ohlen, D.; Zhu, Z.; Yang, L.; Merchant, J. Development of a global land cover characteristics database and IGBP DISCover from $1 \mathrm{~km}$ AVHRR data. Int. J. Remote Sens. 2000, 21, 1303-1330.

22. Brown, J.F.; Loveland, T.R.; Ohlen, D.O.; Zhu, Z.-L. The global land-cover characteristics database: The users' perspective. Photogramm. Eng. Remote Sens. 1999, 65, 1069-1074.

23. Friedl, M.A.; McIver, D.K.; Hodges, J.C.F.; Zhang, X.Y.; Muchoney, D.; Strahler, A.H.; Woodcock, C.E.; Gopal, S.; Schneider, A.; Cooper, A. et al. Global land cover mapping from MODIS: Algorithms and early results. Remote Sens. Environ. 2002, 83, 287-302.

24. Friedl, M.A.; Sulla-Menashe, D.; Tan, B.; Schneider, A.; Ramankutty, N.; Sibley, A.; Huang, X. MODIS Collection 5 global land cover: Algorithm refinements and characterization of new datasets. Remote Sens. Environ. 2010, 114, 168-182.

25. Friedman, J.; Hastie, T.; Tibshirani, R. Additive logistic regression: A statistical view of boosting (with discussion and a rejoinder by the authors). Ann. Stat. 2000, 28, 337-407.

26. Nachtergaele, F.; Batjes, N. Harmonized World Soil Database. FAO: Rome, Italy, 2012.

27. Carlson, T.N.; Ripley, D.A. On the relation between NDVI, fractional vegetation cover, and leaf area index. Remote Sens. Environ. 1997, 62, 241-252.

28. Mann, H.B. Nonparametric tests against trend. Econometrica 1945, 13, 245-259.

29. Kendall, M.G. Rank Correlation Methods; Charles Griffin \& Company Limited: London, UK. 1975.

30. Gilbert, R.O. Statistical Methods for Environmental Pollution Monitoring; John Wiley \& Sons: New York, NY, USA, 1987.

31. Jaagus, J. Climatic changes in Estonia during the second half of the 20th century in relationship with changes in large-scale atmospheric circulation. Theor. Appl. Climatol. 2006, 83, 77-88.

32. Nalley, D.; Adamowski, J.; Khalil, B. Using discrete wavelet transforms to analyze trends in streamflow and precipitation in Quebec and Ontario (1954-2008). J. Hydrol. 2012, 475, 204-228.

33. Tabari, H.; Marofi, S. Changes of pan evaporation in the west of Iran. Water Resour. Manag. 2011, 25, 97-111.

34. Hamed, K.H. Exact distribution of the Mann-Kendall trend test statistic for persistent data. J. Hydrol. 2009, 365, 86-94. 
35. Zhang, X.; Harvey, K.D.; Hogg, W.; Yuzyk, T.R. Trends in Canadian streamflow. Water Resour. Res. 2001, 37, 987-998.

36. Gocic, M.; Trajkovic, S. Analysis of changes in meteorological variables using Mann-Kendall and Sen's slope estimator statistical tests in Serbia. Glob. Planet. Chang. 2013, 100, 172-182.

37. Hamed, K.H.; Ramachandra Rao, A. A modified Mann-Kendall trend test for autocorrelated data. J. Hydrol. 1998, 204, 182-196.

38. Sen, P.K. Estimates of the regression coefficient based on Kendall's tau. J. Am. Stat. Assoc. 1968, 63, 1379-1389.

39. Tabari, H.; Hosseinzadeh Talaee, P. Analysis of trends in temperature data in arid and semi-arid regions of Iran. Glob. Planet. Chang. 2011, 79, 1-10.

40. Kulkarni, A.; von Storch, H. Monte carlo experiments on the effect of serial correlation on the Mann-Kendall test of trend. Meteorol. Z. 1995, 4, 82-85.

41. Von Storch, H.; Navarra, A. Analysis of Climate Variability: Applications of Statistical Techniques; Springer: Berlin, Germany, 1995.

42. Salas, J.D. Applied Modeling of Hydrologic Times Series; Water Resources Publication: Littleton, CO, USA, 1980.

43. Kendall, M.G.; Alan, S. The Advanced Theory of Statistics: Design and Analysis, and Time-Series; Charles Griffin \& Company Limited: London, UK, 1968.

44. Anderson, R.L. Distribution of the serial correlation coefficient. Ann. Math. Stat. 1942, 13, 1-13.

45. Ronald Eastman, J.; Sangermano, F.; Ghimire, B.; Zhu, H.; Chen, H.; Neeti, N.; Cai, Y.; Machado, E.A.; Crema, S.C. Seasonal trend analysis of image time series. Int. J. Remote Sens. 2009, 30, 2721-2726.

46. Alcaraz-Segura, D.; Liras, E.; Tabik, S.; Paruelo, J.; Cabello, J. Evaluating the consistency of the 1982-1999 NDVI trends in the iberian peninsula across four time-series derived from the AVHRR sensor: LTDR, GIMMS, FASIR, and PAL-II. Sensors 2010, 10, 1291-1314.

47. Fensholt, R.; Rasmussen, K.; Kaspersen, P.; Huber, S.; Horion, S.; Swinnen, E. Assessing land degradation/recovery in the African Sahel from long-term earth observation based primary productivity and precipitation relationships. Remote Sens. 2013, 5, 664-686.

48. Parmentier, F.-J.W.; Christensen, T.R.; Sorensen, L.L.; Rysgaard, S.; McGuire, A.D.; Miller, P.A.; Walker, D.A. The impact of lower sea-ice extent on arctic greenhouse-gas exchange. Nat. Clim. Chang. 2013, 3, 195-202.

49. Bintanja, R.; Graversen, R.G.; Hazeleger, W. Arctic winter warming amplified by the thermal inversion and consequent low infrared cooling to space. Nat. Geosci. 2011, 4, 758-761.

50. Screen, J.A.; Simmonds, I. The central role of diminishing sea ice in recent arctic temperature amplification. Nature 2010, 464, 1334-1337.

51. Chapin, F.S.; Sturm, M.; Serreze, M.C.; McFadden, J.P.; Key, J.R.; Lloyd, A.H.; McGuire, A.D.; Rupp, T.S.; Lynch, A.H.; Schimel, J.P. et al. Role of land-surface changes in arctic summer warming. Science 2005, 310, 657-660.

52. Riihela, A.; Manninen, T.; Laine, V. Observed changes in the albedo of the arctic sea-ice zone for the period 1982-2009. Nat. Clim. Chang. 2013, doi:10.1038/nclimate1963. 
53. Arrigo, K.R.; Perovich, D.K.; Pickart, R.S.; Brown, Z.W.; van Dijken, G.L.; Lowry, K.E.; Mills, M.M.; Palmer, M.A.; Balch, W.M.; Bahr, F.; et al. Massive phytoplankton blooms under arctic sea ice. Science 2012, doi:10.1126/science.1215065.

54. Tucker, C.J.; Slayback, D.A.; Pinzon, J.E.; Los, S.O.; Myneni, R.B.; Taylor, M.G. Higher northern latitude normalized difference vegetation index and growing season trends from 1982 to 1999. Int. J. Biometeorol. 2001, 45, 184-190.

55. Post, E.; Bhatt, U.S.; Bitz, C.M.; Brodie, J.F.; Fulton, T.L.; Hebblewhite, M.; Kerby, J.; Kutz, S.J.; Stirling, I.; Walker, D.A. Ecological consequences of sea-ice decline. Science 2013, 341, 519-524.

56. Macias-Fauria, M.; Forbes, B.C.; Zetterberg, P.; Kumpula, T. Eurasian arctic greening reveals teleconnections and the potential for structurally novel ecosystems. Nat. Clim. Chang. 2012, 2, 613-618.

57. Walther, G.-R.; Post, E.; Convey, P.; Menzel, A.; Parmesan, C.; Beebee, T.J.; Fromentin, J.-M.; Hoegh-Guldberg, O.; Bairlein, F. Ecological responses to recent climate change. Nature 2002, 416, 389-395.

58. Houghton, J.T.; Ding, Y.; Griggs, D.J.; Noguer, M.; van der LINDEN, P.J.; Dai, X.; Maskell, K.; Johnson, C. Climate Change 2001: The Scientific Basis; Cambridge University Press: Cambridge, UK, 2001.

59. Jeong, S.-J.; Ho, C.-H.; Gim, H.-J.; Brown, M.E. Phenology shifts at start vs. End of growing season in temperate vegetation over the northern hemisphere for the period 1982-2008. Glob. Chang. Biol. 2011, 17, 2385-2399.

60. Nemani, R.R.; Keeling, C.D.; Hashimoto, H.; Jolly, W.M.; Piper, S.C.; Tucker, C.J.; Myneni, R.B.; Running, S.W. Climate-driven increases in global terrestrial net primary production from 1982 to 1999. Science 2003, 300, 1560-1563.

61. Karl, T.R.; Trenberth, K.E. Modern global climate change. Science 2003, 302, 1719-1723.

(C) 2014 by the authors; licensee MDPI, Basel, Switzerland. This article is an open access article distributed under the terms and conditions of the Creative Commons Attribution license (http://creativecommons.org/licenses/by/3.0/). 